\title{
A Cross-Sectional Survey to Determine the Prevalence of Cardiovascular Disease Risk Factors in an Understudied Population in
} Sierra Leone

\author{
Fiona E. Strasserking ${ }^{*}$, Roger J. Bick ${ }^{1}$, James B. W. Russell ${ }^{2}$, Yong-Jian Geng ${ }^{1}$ \\ ${ }^{1}$ McGovern Medical School, University of Texas, Houston, Texas, USA \\ ${ }^{2}$ Ministry of Health, Freetown, Sierra Leone \\ Email: *fstrasserking99@gmail.com
}

Received 29 September 2015; accepted 26 January 2016; published 29 January 2016

Copyright (C) 2016 by authors and Scientific Research Publishing Inc.

This work is licensed under the Creative Commons Attribution International License (CC BY). http://creativecommons.org/licenses/by/4.0/

(c) (i) Open Access

\begin{abstract}
To document the prevalence of risk factors for cardiovascular disease in an unstudied community, a survey of 130 participants from different areas of Sierra Leone was performed. The focus was on cardiovascular disease because its prevalence had not been studied and World Health Organization (WHO) reports on Non-Communicable Diseases (NCD) prevalence were extrapolations and not from actual data. Resting blood pressure, fasting blood glucose, fasting lipid levels and carotid intima media thickness (CIMT) were measured. Mean blood pressure in men was slightly lower than in women (132/87 $\mathrm{mmHg}$ and $139 / 90 \mathrm{mmHg}$ respectively), mean fasting blood glucose levels were $<100 \mathrm{mg} / \mathrm{dL}$ in both groups and mean fasting total cholesterol was higher in women than in men (206 mg versus $193.5 \mathrm{mg} / \mathrm{dL}$ ). Mean fasting low density lipoprotein levels were similar in both groups, $129 \mathrm{mg} / \mathrm{dL}$ in men and $133 \mathrm{mg} / \mathrm{dL}$ in women. Mean fasting high density cholesterol was $47.2 \mathrm{mg} / \mathrm{dL}$ in men and $55.5 \mathrm{mg} / \mathrm{dL}$ in women and CIMT values were similar in both groups, with $60 \%$ above the $75^{\text {th }}$ percentile. This study demonstrated a prevalence of cardiovascular risk factors in this population with mean BP placing both men and women in pre-hypertension or stage 1 hypertension ranges and elevated mean low density lipoprotein levels. Fasting total cholesterol, blood glucose and high density lipoprotein were within normal ranges. Mean CIMT values for men and women placed them at risk for subclinical atherosclerosis.
\end{abstract}

\section{Keywords}

Cardiac Disease, Lifestyle, Non-Communicable Diseases, Risk Factors, Socioeconomic Background

\footnotetext{
${ }^{*}$ Corresponding author.
}

How to cite this paper: Strasserking, F.E., Bick, R.J., Russell, J.B.W. and Geng, Y.-J. (2016) A Cross-Sectional Survey to Determine the Prevalence of Cardiovascular Disease Risk Factors in an Understudied Population in Sierra Leone. World Journal of Cardiovascular Diseases, 6, 21-29. http://dx.doi.org/10.4236/wjcd.2016.61004 


\section{Introduction}

In 2011, the WHO report on NCD estimated the mortality rate in Sierra Leone due to cardiovascular disease and other non-communicable disease was $18 \%$ of all deaths. Three years later in the 2014 report, the rate had increased to $26 \%$ with cardiovascular diseases representing a large proportion of these deaths [1]. Years earlier in 1996, Professor Sir Henry Marmot published his research concerning socio-economic factors and cardiovascular disease and concluded that the increased mortality rate in eastern countries was possibly due to "westernization" [2]. Over two decades later, when Murphy et al. carried out a cross-sectional survey in rural Uganda, they too concluded that socioeconomic status was associated with NCD risk factors in that population [3].

According to the World Health Organization (WHO), diseases such as obesity, once a problem in primarily high-income countries, are now on the rise in low and medium income countries, particularly the WHO African and American Regions. In addition, it was noted that the prevalence of hypertension was highest in low income countries in Africa where a comprehensive healthcare infrastructure is lacking [4]. The incidence of NCDs and resulting deaths from associated complications is thought to have dramatically risen in these countries, suggesting that either NCDs are now being routinely reported, or promotion and adoption of a healthy lifestyle has not become a priority in countries where western lifestyle is now increasing. There have been suggestions that the introduction of "westernized" diet and a shift from agriculture to more processed foods are major factors in this ever-growing problem [5].

A study published in Nigeria by the Department of Human Nutrition further established that these detrimental changes in the diet of people in African countries were a major concern, and that was due to industrialization and associated lifestyle alterations, there is now an increased problem of a greater risk for cardiovascular diseases [6]. There is an overwhelming lack of data in Sierra Leone regarding NCD sand associated problems, and the purpose of this study was to document findings regarding these diseases to assist the healthcare community in better understanding risk markers and patient susceptibility. As in many other West African countries, diagnostics and treatment options for myocardial infarction and cerebrovascular disease are limited, making early identification of risk factors of paramount importance for instituting lifestyle modifications and associated beneficial outcomes, while also being cost effective for patients in poorer communities [7].

Using CIMT as a predictor of cardiovascular disease has been widely studied. In addition to the accepted risk factors such as hypertension and high levels of low density lipoprotein (LDL), mean CIMT has been suggested as an accurate, independent, noninvasive predictor of impending coronary heart disease [8]-[13]. Recently published studies have concluded that mean CIMT, together with the presence of plaque in the carotid artery, is better predictor of future cardiovascular problems than with CIMT alone [14]-[19].

Other disease trends have also had a major impact on healthcare in Sierra Leone. The rise in HIV infection rates necessitates the use of drugs like protease inhibitors which have been shown to be associated with an increased risk of myocardial infarction. This increased risk is thought to be almost certainly due to dyslipidemia, as was published by the DAD study group [20]. In addition, there have been major increases in other communicable diseases due to a combination of poor sanitation, clustering of populations and poor healthcare infrastructure (World Health Organization, Sierra Leone;

http://www.whosierraleone.org/2_programs/communicabledisease.html).

\section{Methods}

The protocol was approved by the Institutional Review Boards of the University of Texas Health Science Center in Houston (HSC-GEN-12-0228) and the Ministry of Health in Sierra Leone. Informed consent was obtained from participants in their native language in a total of four weeks in May 2012 and June 2013 and all volunteers were black Africans.

A survey of participants aged between 25 and 77 years, was performed in three regions of Sierra Leone over the course of four weeks. Individuals were sampled from different socio-economic backgrounds, from the capital Freetown to the west (per capita income varies a great deal, so values here are estimates from 2014; Freetown $\$ 868$ to $\$ 1,690$, Port Loko in the north; \$624 - \$868 and N'jala in the south; \$450 - \$690), shown on the included map. Volunteers were solicited from their respective communities via public announcements on the radio and by word of mouth through local community leaders with the request to fast at least 8 hours prior to testing. Exclusion criteria included individuals less than 25 years old and those who were pregnant. The screening was performed by medical personnel fluent in the local dialect, using an approved questionnaire. No medical record 


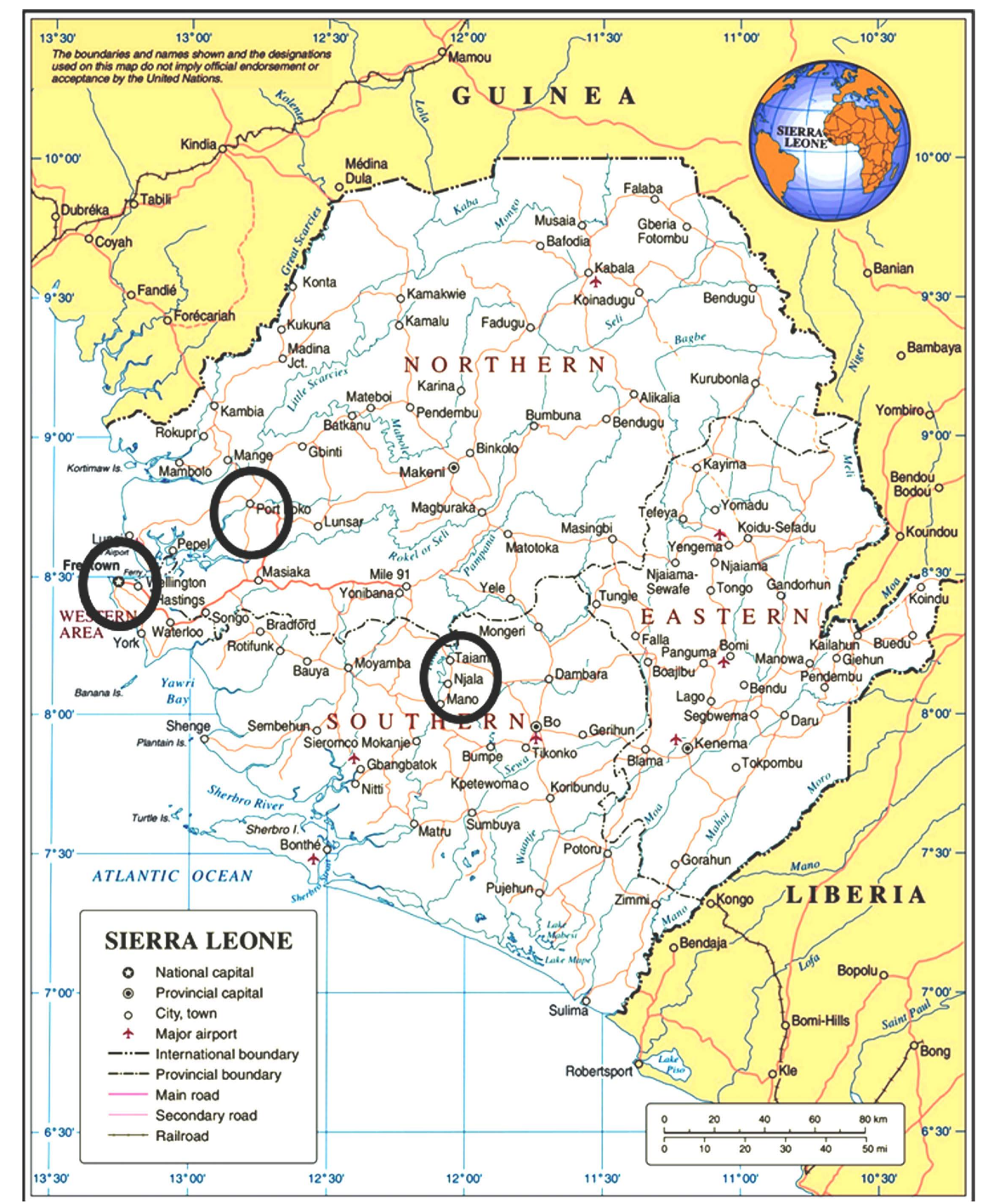

http://www.un.org/Depts/Cartographic/map/profile/sierrale.pdf

review was performed and no identifying information was obtained on the questionnaire. There were no incentives offered and free health counseling, as well as test results, was provided to participants, something which many would not have been able to afford.

Procedures were explained to the participants, and a discussion of test results was given, including recommendations for life-style modification. With a finding of abnormal test results, follow up was recommended with their primary care providers or the onsite provider. Three participants had no blood pressures recorded because of prior mastectomies; five had no fasting blood levels measured due to not fasting at the time of screening and not returning for fasting level measurements; one participant refused to have carotid imaging performed. After consent was obtained, data was collected on the approved questionnaire, including demographic information, a brief medical, as well as a brief social background including HIV status and cigarette smoking. Participants were asked about prior HIV testing and results whether positive or negative. A majority of the volunteers (96\%) were unaware of their status and no HIV testing was performed during this study. Participants were allowed to rest for at least 5 minutes before subsequent screening.

Bilateral resting blood pressure was measured in the seated upright position using a standard medical sphygmomanometer and an appropriate sized cuff. Fasting blood glucose levels were obtained with a standard TRUE result TM glucometer (Nipro Diagnostics Inc., Fort Lauderdale, FL, USA). Fasting lipid levels, including cholesterol, triglyceride, high density lipoprotein and low density lipoprotein, were obtained using a CardioChekP. 
Aanalyzer TM (Polymer Technology Systems Inc., Indianapolis, IN, USA).With the subject supine, B-mode images of their bilateral common carotid artery (CCA) and their bilateral carotid bulb were obtained with a GE Vivid ETM ultrasound machine fitted with an 8L-RS high frequency linear array transducer (GE Healthcare, Waukesha, WI, USA). Transverse and longitudinal images were obtained and evaluated onsite for the presence of clinically significant plaque formation. Longitudinal images of the carotid artery were recorded in 3 - 5 heart beat cine loops with optimal visualization of the near and far walls of the distal $1 \mathrm{~cm}$ of the CCA and the proximal carotid bulb. Images were recorded in the longitudinal plane from three different optimal acquisition angles of incidence showing near and far wall double lines indicating true perpendicular scanning planes by the same sonographer experienced in obtaining images for CIMT measurements (Figure 1), as recommended by the American Society of Echocardiography (Morrisville, North Carolina, USA) and the Society of Vascular Medicine (Deerfield, Illinois, USA) [21].

\section{Data Analysis}

Resting CIMT images were analyzed using the Carotid Analyzer for Research by Medical Imaging Applications (www.mia.llc.com). Measurements of the far wall of the distal $1 \mathrm{~cm}$ of the CCA were recorded at three different optimal angles and were then averaged. Resting blood pressures, fasting glucose and cholesterol values were tabulated to interpret prevalence among different age groups with corresponding group CIMT values. Comparisons of mean values between males and females was performed and presented in tabular and graphical formats.

\section{Results}

Figure 1 shows an example ultrasound B-mode capture to detail optimal intima-media thickness of a carotid artery.

Table 1 details the demographic data of the 130 participants in this study including age, smoking history, history of PVD, stroke and/or heart disease, diabetes and medications.

Figure 2 and Figure 3 are histograms presented to give an overview of changes in total cholesterol (TC, Figure 2(a)), triglyceride levels (TG, Figure 2(b)), LDL (Figure 3(a)) and HDL (Figure 3(b)). As can be seen there was a slight trend of increases in TC TG and LDL with age, but no significant differences were noted, while HDL levels remained level.

Given this somewhat surprising finding, we plotted age versus both right and left carotid intima-media thickness and found a definite association between increased intima-media thickening and age in both male and female subjects (Figure 4).

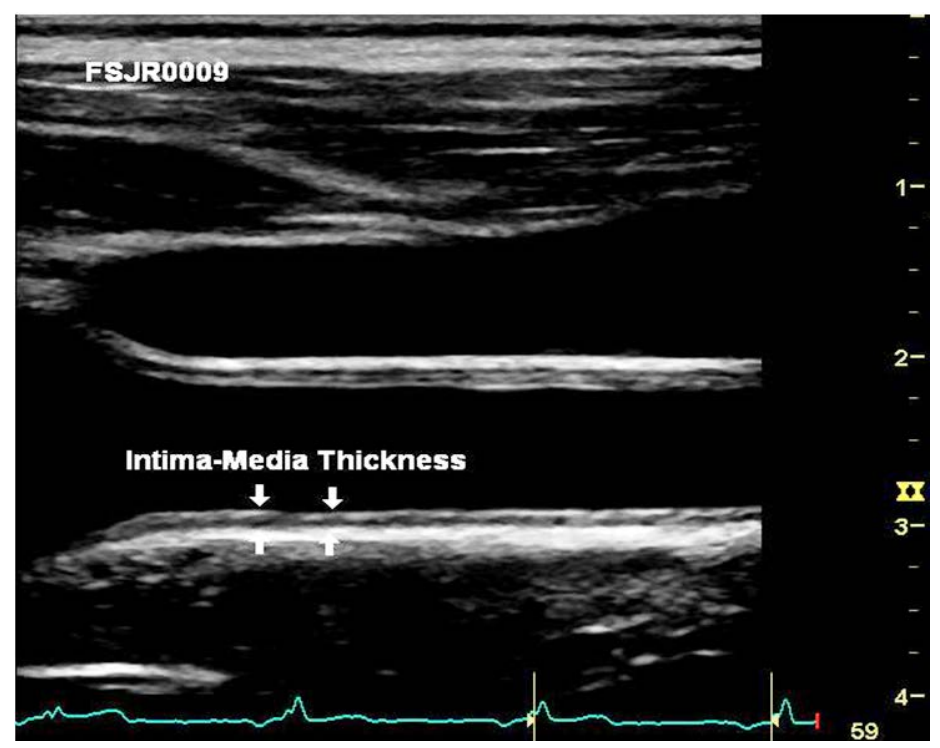

Figure 1. Carotid intima-media thickness measurement at optimal depth, on the R-wave. 
Table 1. Demographic information of the participants.

\begin{tabular}{ccccc}
\hline Demographic & Yes & No & Total & $\begin{array}{c}\text { Confidence } \\
\text { interval }\end{array}$ \\
\hline Known history of heart disease & $6(4.6 \%)$ & 124 & 130 & $1.6-10.4$ \\
Known history of stroke & $1(0.8 \%)$ & 129 & 130 & $0.3-1.7$ \\
Known history of peripheral vascular disease & 0 & 130 & 130 & - ------ \\
Cigarette smoking (cigarettes per day 3 - 18) & $10(7.7 \%)$ & 120 & 130 & $2.7-17.3$ \\
Known history of hypertension & $47(36 \%)$ & 83 & 130 & $14-80$ \\
On medications & $30(23 \%)$ & 17 & 118 & $8-52$ \\
Known history of diabetes & $12(9.2 \%)$ & 5 & $3.2-20.8$ \\
On medications & $7(5.4 \%)$ & 5 & $2-12$ \\
\hline
\end{tabular}
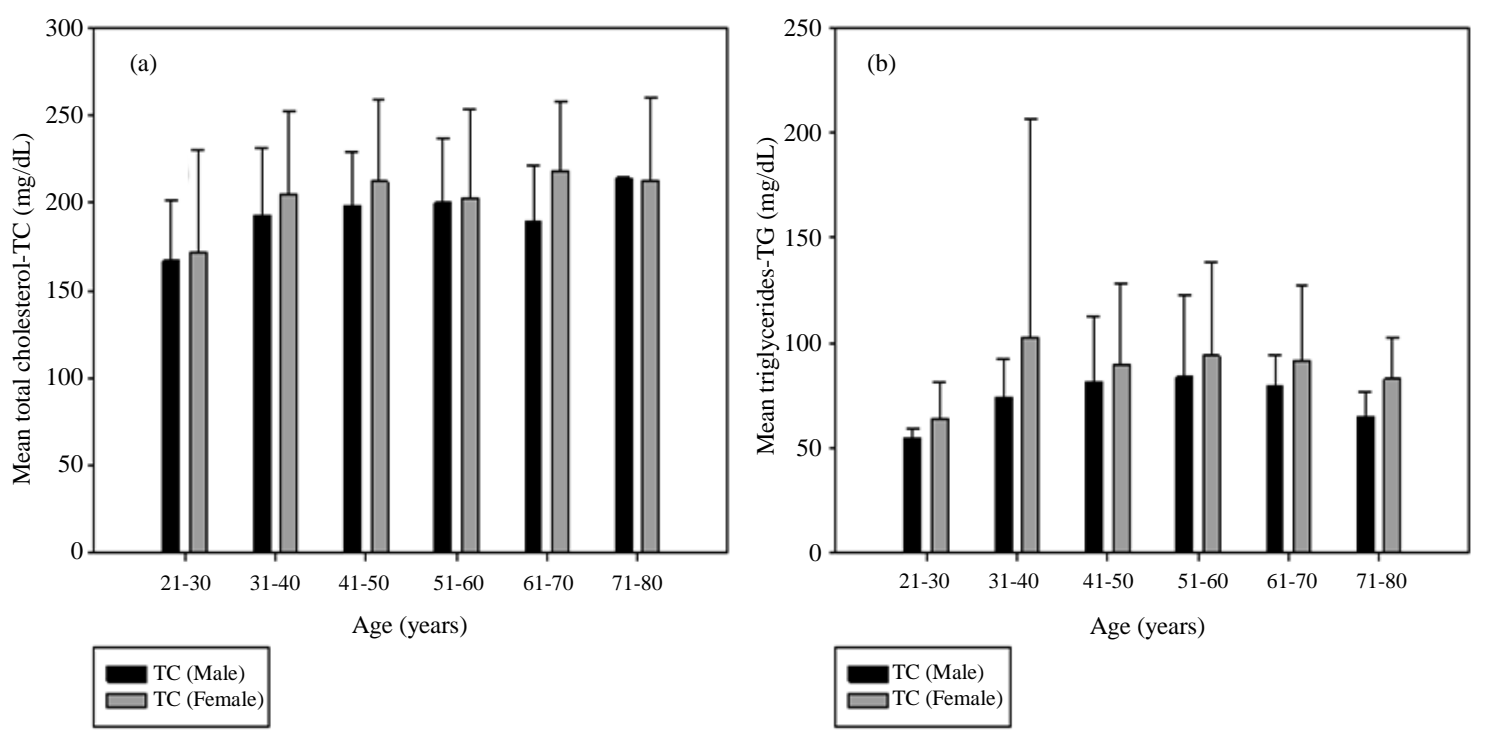

Figure 2. This figure shows histograms to give an overview of changes in total cholesterol (TC, Figure 2(a)) and trigylceride levels (TG, Figure 2(b)). As can be seen there was a slight trend of increases in both TC and TG with age, but no significant differences were noted $(\mathrm{TC}=$ total cholesterol; $\mathrm{TG}=$ triglycerides).
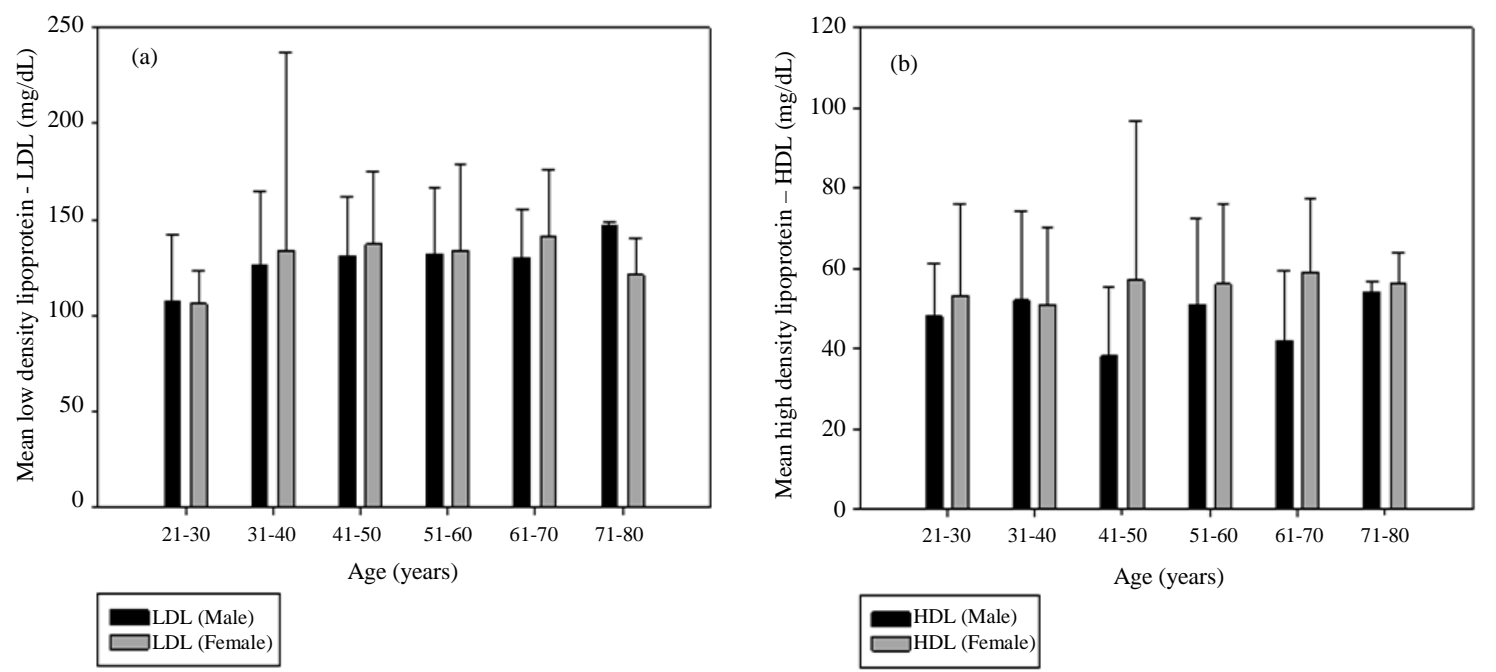

Figure 3. This figure shows histograms to give an overview of changes LDL (Figure 3(a)) and HDL (Figure 3(b)). As can be seen there was a slight trend of an increase in LDL with age, but no significant differences were noted, while HDL levels remained stable (HDL = high density lipoprotein; LDL = low density lipoprotein). 


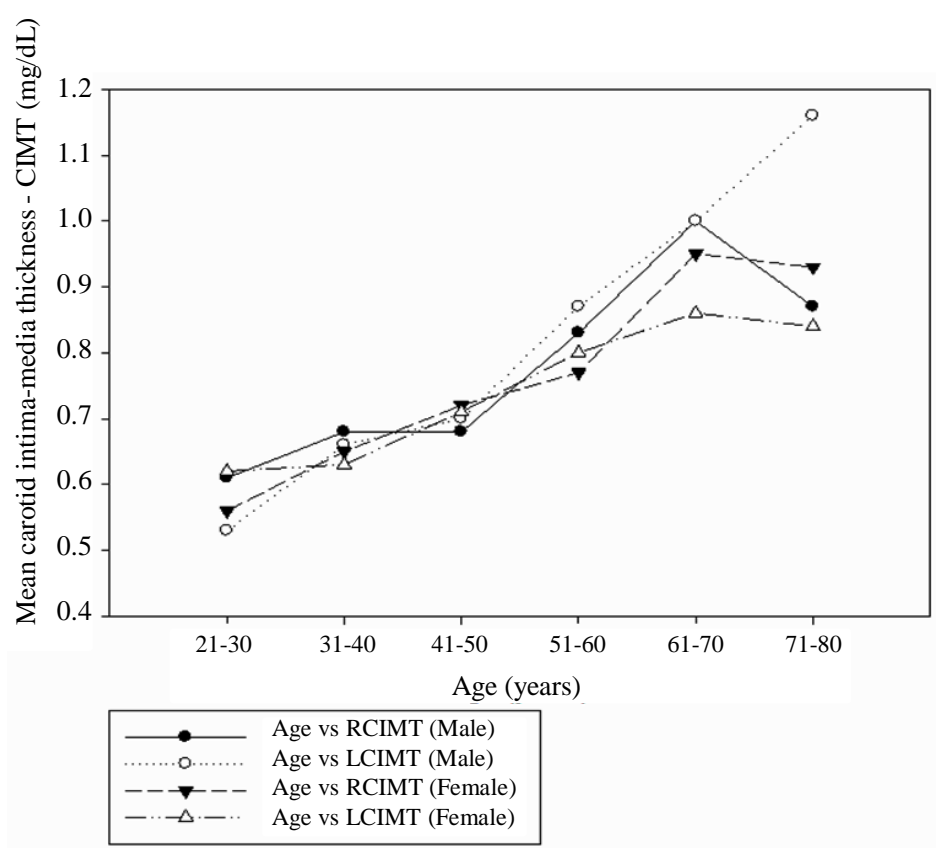

Figure 4. Plot of age versus both right and left carotid intima-media thickness, detailing a direct association between increased thickening and age, in both male and female subjects (LCIMT = left carotid intima-media thickening; RCIMT = right carotid-intima thickening).

To further delineate and assign changes of potential risk factors (LDL, HDL, systolic BP and diastolic BP) with carotid thickening, each was plotted against CMIT as shown in Figure 5. It is apparent that there is a strong correlation between all the markers (LDL, TC, SBP, DBP) and carotid thickening, suggesting that even slight elevations could indicate problems with narrowing of vessel lumens.

\section{Discussion and Study Limitations}

The aim of this study was to document the prevalence of cardiovascular disease risk factors in Sierra Leone and provide the local healthcare community some information that would be useful to them in risk stratifying this population and provide preventative interventions to high risk individuals. The study provides relevant, up-to-date data to the Sierra Leone healthcare system that will bring awareness to a much overlooked health issue and that will hopefully shed more light on the state of non-communicable diseases in the country.

This work was undertaken because the cost of healthcare in Sierra Leone was more than most patients could afford even for those who actually have access to it. A study published by the Médecins Sans Frontières concluded that the no cash-no care policy in Sierra Leone and other developing countries was placing a financial barrier to patients in need of care [22]. Many reports have documented the rise in NCDs in poorer countries, coupled with the undue burden these diseases place on an already fragile infrastructure. Last year an NCD policy was launched in Sierra Leone with the hope of creating a registry and providing up to date information on their prevalence. We hope that the data we have collected from three regions of this country will go towards this database and provide more information for the healthcare community of Sierra Leone and aid organizations.

CIMT has been shown to be an independent predictor of future cardiovascular events and as seen in the study, it appears to correlate directly with increased age, hypertension and dyslipidemia. There are also a number of previous reports linking certain lifestyles and traits, such as high cholesterol, smoking and diabetes to CIMT and the reliability of using carotid thickening as an indicator of impending blood pressure and cardiovascular problems has a sound basis [23]-[26]. Our hope is that this relatively cheap and safe technology, when combined with blood pressure readings and lipid measurements, also cheap and safe, can be used as an indicator that early intervention is required for patients with these risk factors.

We do acknowledge that some limitations exist in this study, one being the fact that we were unable to definitively say whether a participant did or did not have heart disease based on the data we collected. However, we 

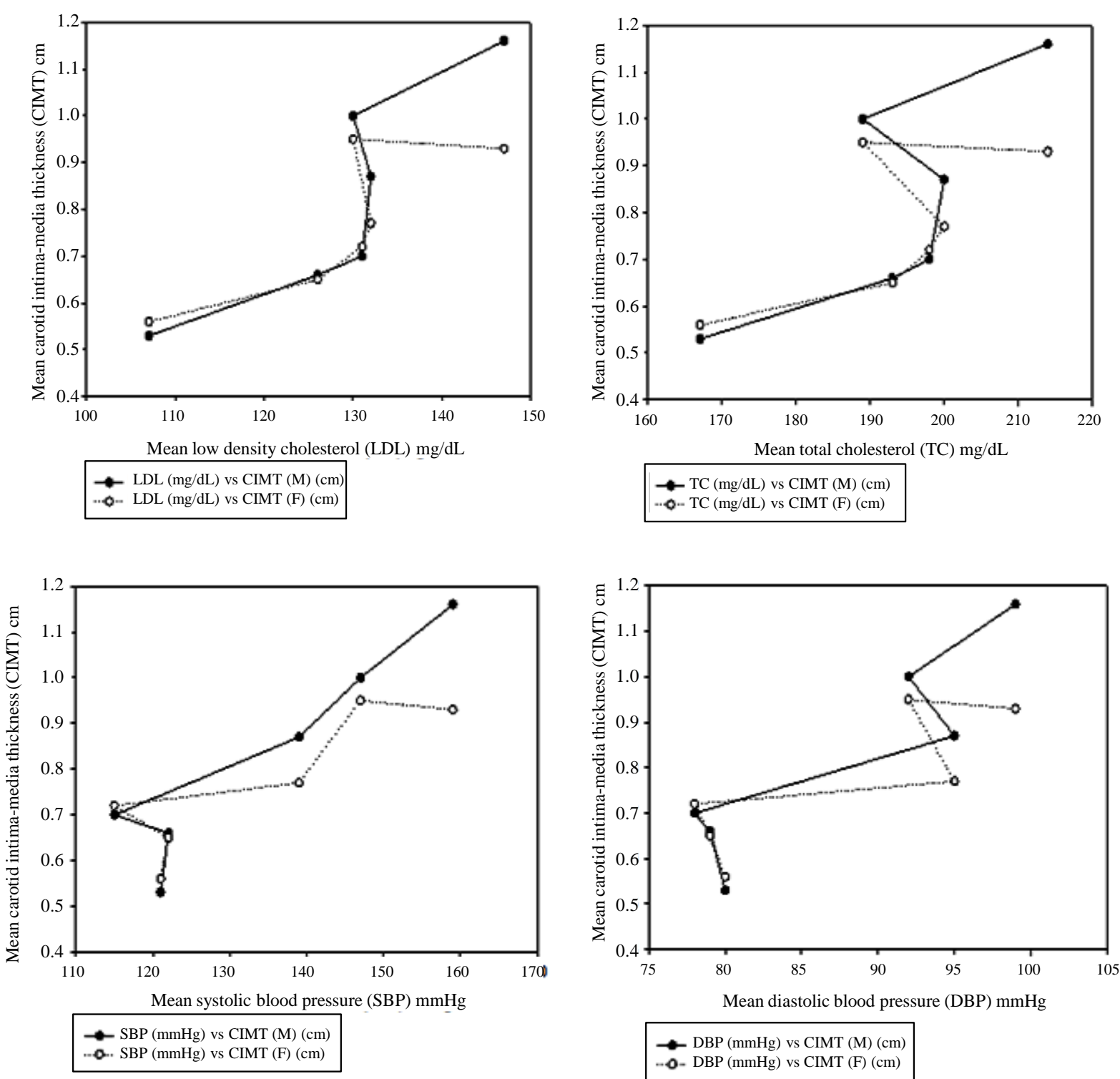

Figure 5. LDL, HDL, systolic BP and diastolic BP plotted against CMIT as shown. There is a strong correlation between all the markers (LDL, TC, SBP, DBP) and carotid thickening (BP = blood pressure; CMIT = carotid media-intima thickening; DBP = diastolic blood pressure; HDL = high density lipoprotein; LDL = low density lipoprotein; SBP = systolic blood pressure).

are able to interpret the data because of established guidelines and can conclude from individual test results whether a patient is at increased risk for cardiovascular events. Looking at the means of the data, it becomes apparent that the suggestion that the overall trend paints a bleak picture for cardiovascular disease in our patient group is not entirely true. Another limitation of this study is the disparity in education, health literacy, access to healthcare, nutritional status and sanitary conditions among the participants. These factors undoubtedly affect the overall health of individuals and we hope the fact that we sampled from such a wide variety will allow for a broader picture to be painted.

\section{References}

[1] World Health Organization-NCD Country Profiles, 2, 2011 \& 2014, Sierra Leone. http://www.aho.afro.who.int/profiles information/index.php/Sierra Leone:Index

[2] Marmot, M.G. (1996) Socio-Economic Factors in Cardiovascular Disease. Journal of Hypertension, 14, S201-S205. 
[3] Murphy, G., Asiki, G., Ekoru, K., Nsubuga, R.N., Nakiyingi-Miiro, J., Young,E.H., Seeley, J., Sandhu, M.S. and Kamali, A. (2013) Sociodemographic Distribution of Non-Communicable Disease Risk Factors in Rural Uganda: A Cross-Sectional Study. International Journal of Epidemiology, 42, 1740-1753. http://dx.doi.org/10.1093/ije/dyt184

[4] WHO Global Action Plan for the Prevention and Control of Non-Communicable Diseases 2013-2020. http://apps.who.int/iris/bitstream/10665/94384/1/9789241506236_eng.pdf

[5] Boutayeb, A. and Boutayeb, S. (2005) The Burden of Non-Communicable Diseases in Developing Countries. International Journal for Equity in Health, 4, 2. http://dx.doi.org/10.1186/1475-9276-4-2

[6] Samuel. F. and Atinmo, F. (2008) Obesity and Cardiovascular Diseases: The Risk Factor in African Diets. Forum on Public Policy, Urbana, IL, 1-15. http://forumonpublicpolicy.com/archivespring08/samuel.pdf

[7] Kishore, S. and Michelow, M. (2011) The Global Burden of Disease. Public Health in the $21^{\text {st }}$ Century. Global Issues in Public Health (Madelon L. Finkel, ed.), Ch1, 29-45, ABC-CLIO (Santa Barbara, CA, USA). http://skishore.wikispaces.com/file/view/The+Global+Burden+of+Disease.pdf

[8] Chambless, L., Heiss, G., Folsom, A.R., Rosamond, W. and Szklo, M. (1997) Association of Coronary Heart Disease Incidence with Carotid Arterial Wall Thickness and Major Risk Factors: The Atherosclerosis Risk in Communities (ARIC) Study, 1987-1993. American Journal of Epidemiology, 146, 483-494. http://dx.doi.org/10.1093/oxfordjournals.aje.a009302

[9] Stein., J,H., Korcarz, C.E., Hurst, R.T., Lonn, E., Kendall, C.B., Mohler, E.R., Najjar, S.S., Rembold, C.M. and Post, W.S. (2008) Use of Carotid Ultrasound to Identify Subclinical Vascular Disease and Evaluate Cardiovascular Disease Risk: A Consensus Statement from the American Society of Echocardiography Carotid Intima-Media Thickness Task Force Endorsed by the Society of Vascular Medicine. Journal of American Society of Echocardiology, 21, 93-111. http://dx.doi.org/10.1016/j.echo.2007.11.011

[10] Djaberi, R., Schuijf, J.D., Jukema, J.W., Rabelink, T.J., Stokkel, M.P., Smit, J.W., de Koning, E.J. and Bax, J.J. (2010) Increased Carotid Intima-Media Thickness as a Predicator of the Presence and Extent of Abnormal Myocardial Perfusion in Type 2 Diabetes. Diabetes Care, 33, 372-374. http://dx.doi.org/10.2337/dc09-1301

[11] Sharma, P., Lohani, B. and Chataut, S.P. (2009) Ultrasonographic Evaluation of Carotid Intima-Media Thickness in Hypertensive and Normotensive Individuals. Journal of Nepal Medical College, 11, 133-135.

[12] Hansa, G., Bhargava, K., Bansal, M., Tandon, S. and Kasliwal, R.R. (2003) Carotid Intima-Media Thickness and Coronary Artery Disease: An Indian Perspective. Asian Cardiovascular and Thoracic Surgery Annals, 11, $217-221$. http://dx.doi.org/10.1177/021849230301100308

[13] Tarzamni, M.K., Salehi, R., Givian, F. and Farhang, S. (2006) Association of Carotid Intima-Media Thickness with the Presence and Severity of Coronary Artery Disease. Neuroscience, 11, 308-311.

[14] Lorenz, M.W., Schafer, C., Steinmetz, H. and Sitzer, M. (2010) Is Carotid Intima Media Thickness Useful for Individual Prediction of Cardiovascular Risk? Ten-Year Results from the Carotid Atherosclerosis Progression Study (CAPS). European Heart Journal, 31, 2041-2048. http://dx.doi.org/10.1093/eurheartj/ehq189

[15] Bots, M.L., Groenewegen, K.A., Anderson, T.J., Britton, A.R., Dekker, J.M., Engström, G., Evans, G.W., de Graaf, J., Grobbee, D.E., Hedblad, B., Hofman, A., Holewijn, S., Ikeda, A., Kavousi, M., Kitagawa, K., Kitamura, A., Ikram, M.A., Lonn, E.M., Lorenz, M.W., Mathiesen, E.B., Nijpels, G., Okazaki, S., O’Leary, D.H., Polak, J.F., Price, J.F., Robertson, C., Rembold, C.M., Rosvall, M., Rundek, T., Salonen, T., Sitzer, M., Stehouwer, C.D., Franco, O.H., Peters, S.A. and den Ruijter, H.M. (2014) Common Carotid Intima-Media Thickness Measurements Do Not Improve Cardiovascular Risk Prediction in Individuals With Elevated Blood Pressure. The USE-IMT Collaboration. Hypertension, 63, 1173-1181. http://dx.doi.org/10.1161/HYPERTENSIONAHA.113.02683

[16] Hester, M., Ruijter, D., Peters, S.A.E., Anderson, T.J., Britton, A.R., Dekker, J.M., Eijkemans, M.J., Engström, G., Evans, G.W., de Graaf, J., Grobbee, D.E., Hedblad, B., Hofman, A., Holewijn, S., Ikeda, A., Kavousi, M., Kitagawa, K., Kitamura, A., Koffijberg, H., Lonn, E.M., Lorenz, M.W., Mathiesen, E.B., Nijpels, G., Okazaki, S., O’Leary, D.H., Polak, J.F., Price, J.F., Robertson, C., Rembold, C.M., Rosvall, M., Rundek, T., Salonen, J.T., Sitzer, M., Stehouwer, C.D.A., Witteman, J.C., Moons, K.G. and Bots, M.L. (2012) Common Carotid Intima-Media Thickness Measurements in Cardiovascular Prediction. A Meta-Analysis. Journal of the American Medical Association, 308, 2455-2456.

[17] Polak, J.F., Pencina, M.J., Pencina, K.M., O’Donnell, C.J., Wolf, P.A.D. and Agostino Sr., R.B. (2011) Carotid-Wall Intimal-Media Thickness and Cardiovascular Events. New England Journal of Medicine, 365, 213-221. http://dx.doi.org/10.1056/NEJMoa1012592

[18] Zielinski, T., Dzielinska, Z., Januszewicz, A., Rynkun, D., Makowiecka Ciesla, M., Tycynski, P., Prejbisz, A., Damkow, M., Kadziela, J., Naruszewicz, M., Januszewicz, M., Juraszynski, Z., Kofrewicki, J. and Ruzylio, W. (2007) Carotid Intima-Media Thickness as a Marker of Cardiovascular Risk in Hypertensive Patients with Coronary Artery Disease. American Journal of Hypertension, 20, 1058-1064. http://dx.doi.org/10.1016/j.amjhyper.2007.05.011

[19] Peralta, C.A., Adeney, K.L., Shlipak, M.G., Jacobs Jr., D., Duprez, D., Polak, J., Psaty, B. and Kestenbaum, B.R. (2010) Structural and Functional Vascular Alterations and Incident Hypertension in Normotensive Adults: The Mul- 
ti-Ethnic Study of atherosclerosis. American Journal of Epidemiology, 171, 63-71. http://dx.doi.org/10.1093/aje/kwp319

[20] The DAD Study Group (2007) Class of Antiretroviral Drugs and the Risk of Myocardial Infarction. New England Journal of Medicine, 356, 1723-1735. http://dx.doi.org/10.1056/NEJMoa062744

[21] Roman, M.J., Naqvi, T.Z., Gardin, J.M., Gerhard-Herman, M., Jaff, M. and Mohler, E. (2006) Clinical Application of Noninvasive Vascular Ultrasound in Cardiovascular Risk Stratification: A Report from the American Society of Echocardiography and the Society of Vascular Medicine and Biology. Journal of the American Society for Echocardiology, 19, 943-954. http://dx.doi.org/10.1016/j.echo.2006.04.020

[22] Ponsar, F., Tayler-Smith, K., Phillips, M., Gerard, S., Van Herp, M., Reid, T. and Zachariah, R. (2011) No Cash, No Care: How User Fees Endanger Health—Lessons Learnt Regarding Financial Barriers to Healthcare Services in Burundi, Sierra Leone, Democratic Republic of Congo, Chad, Haiti and Mali. International Health, 3, 91-100. http://dx.doi.org/10.1016/j.inhe.2011.01.002

[23] Giudice, R., Izzo, R., Manzi, M.V., Pagnano, G., Santoro, M., Rao, M.A., Di Renzo, G., De Luca, N. and Trimarco, V. (2012) Lifestyle-Related Risk Factors, Smoking Status and Cardiovascular Disease. High Blood Pressure and Cardiovascular Prevention, 19, 85-92.

[24] Keymel, S., Lalka, C., Rassaf, T., Yeghiazarians, Y., Kelm, M. and Heiss, C. (2008) Impaired Endothelial Progenitor Cell Function Predicts Age-Dependent Carotid Intimal Thickening. Basic Research in Cardiology, 103, 582-586. http://dx.doi.org/10.1007/s00395-008-0742-z

[25] Szarejko-Paradowska, A., Gluba-Brzozka, A., Pietruszynski, R. and Rysz, J. (2015) Assessment of the Relationship between Selected Cardiovascular Risk Factors and the Indices of Intima-Media Thickness and Coronary Artery Calcium Score in Various Stages of Chronic Kidney Disease. International Urology and Nephrology, 47, 2003-2012. http://dx.doi.org/10.1007/s11255-015-1132-8

[26] Wang, P.W., Liou, C.W., Wang, S.T., Eng, H.L., Liu, R.T., Tung, S.C., Chien, W.Y., Lu, Y.C., Kuo, M.C., Hsieh, C.J., Chen, C.H., Chen, J.F., Chu, J.W. and Reaven, G.M. (2002) Relative Impact of Low-Density Lipoprotein-Cholesterol Concentration and Insulin Resistance on Carotid Wall Thickening in Nondiabetic, Normotensive Volunteers. Metabolism, 51, 255-259. http://dx.doi.org/10.1053/meta.2002.29998 